\title{
CRIMEN Y CASTIGO: \\ SEXUALIDAD EN J. M. ARGUEDAS
}

\author{
POR \\ SARA CASTRO-KLAREN \\ Dartmouth College
}

Antes de empezar cualquier comentario sobre la sexualidad en la obra de José María Arguedas hay que dejar bien en claro, para no tener que repetirlo a cada instante, que la sexualidad en el ser humano y hasta en los animales se presenta sin excepción alguna desde el punto de vista del ser masculino. Eso no quiere decir que las mujeres no participen en actos sexuales o dejen de manifestar ciertas y variadas actitudes hacia el sexo, sino que aun en los casos de personajes trazados con rápidas líneas -Marcelina, la Santacrucina, la Kurku, doña Gudelia, doña Gabriela, la Señorita, la Opa-, el que observa, reporta, interpreta y juzga el acontecimiento es una voz, una posición masculina. Este hecho es de suma importancia, ya que en sí indica, no por central, sino más bien por normativo, la posición secundaria y cosificada de la mujer en la(s) sociedad(es) que Arguedas recrea y reconoce como realidad en su obra entera.

Al notar la masculinidad absoluta de la perspectiva y, por tanto, de la problemática es necesario recordar que Arguedas no es en esto original ni menos ideosincrático, sino más bien, y como lo han demostrado cientos de estudios feministas, lleva puestas las anteojeras de un patriarcalismo que cede poco a poco, y cuya última frontera de liberación sea acaso el reconocimiento o mejor el descubrimiento de la humanidad total y diferente de la mujer. No es mi intención aquí hacer un estudio de la dinámica del patriarcalismo, ni tampoco de apuntar cómo impera aún en la obra de un escritor revolucionario como Arguedas. Mi propósito es más circunscrito y modesto. Quiero simplemente sentar las pautas para el análisis del significado de la sexualidad en la narrativa de Arguedas, entendiendo que la visión patriarcal hacia la mujer es algo que tomo por sentado, aunque sea, a nuestras luces, injustificado. 
Sin haber proyectado un análisis de negaciones, se me hace necesario indicar otra salvedad en relación a nuestra acostumbrada visión de la sexualidad. El arquetipo Romeo y Julieta, lo que en mala lengua llamamos amor romántico, se distingue en Arguedas por su ausencia. Pero esa ausencia no constituye ni un misterio ni menos una aberración, sino que se explica dentro de la dinámica afectiva y política del mundo de Arguedas.

Los afectos apasionados, aquellos en que los personajes se sienten desesperadamente infelices o «eternamente felices», gravitan alrededor de momentos de entera alienación o de mística reconciliación con el Bien. Camino de regreso del infernal dormitorio en donde doña Gabriela ha sido violada y donde «el Señor glogloteaba palabras sucias" y «tragaba fuego»; Santiago, que resistió el terror parapetando sus sentidos para no ver ni oír más, al volver a tener conciencia de ellos siente que no oía «la voz del eucalipto en el cielo» (Amor mundo y todos los cuentos, 1967, p. 172), que todo el mundo había sido borrado disolviéndose así en un todo indescifrable que lo hunde en la más profunda soledad. El mismo sentimiento de completa separación le invade la noche del horno viejo, cuando al salir del pueblo acompañando al señor en otra de sus aventuras dantescas, Santiago, intentando calibrar el estado de su relación con las fuerzas benéficas que lo sostienen en los momentos de terror, se da cuenta de que «al salir de la plaza y entrar en una calle muy angosta el mundo se dividió entre suelo y cielo. Así, por el suelo, en toda la sombra, caminaron hasta el horno viejo" (Todos los cuentos..., p. 177). En la oscuridad metafísica Santiago procede hasta su inevitable descenso a los círculos más abismales de la orfandad. Sin embargo, es este mismo torrente pasional que repunta en busca del reencuentro con el Bien. En el caso del personaje-niño (Santiago, Palacitos, Ernesto), lo que moviliza sus actos es la necesidad de compenetración con el padre extraviado, con la armonía de la naturaleza, con la claridad del día y la sensual unión con los objetos mágicos y protectores. Desesperado después de su primer encuentro con Marcelina, enajenado de todo su sentimiento de ser Santiago el inocente, el adolescente intenta deshacer o, mejor dicho, cambiar el significado de su acto sexual transformándose en las nieves del pico Arayá. Sube, esperanzado de encontrarse en la luz, en el espejo del Bien que ha de devolverle una imagen feliz. Al llegar a la cima encuentra la apertura a un mundo anterior a Marcelina y al sexo: «Allí la luz jugaba hondo, los hombres no podían reconocer bien los colores que ardían unos consolando, otros como abriendo precipicios en el corazón mismo... Santiago quedó tranquilo hablando a la nieve: 'Tú nomás eres como yo quiero que todo sea en 
el alma mía, así como estás, padre Arayá, en este rato. Del color del ayrampo purito'» (Todos los cuentos..., p. 187). Santiago/Narciso, que no pudo distinguir su imagen querida en las aguas del remanso, vislumbra en la altura del nevado su reanudada compenetración con el bien y al verse, o mejor dicho, al deshacerse de su humana faz, cae feliz en la luz púrpura del atardecer andino. La púa bipartita del amor romántico, el bien corporizado, el ideal encarnado y sensiblemente localizado en las exigencias de la otredad no parte del mismo tronco ni es en forma alguna análogo o paralelo. Sexo y pasión existen sólo en el divorcio o la enemistad más absoluta.

Cuando los hombres se hacen mayores, el objeto afectivo tampoco lo constituye una mujer. La «felicidad», el éxtasis puede ser el vislumbrar el hacerse realidad un fin político, la victoria de una posición ideológica, el triunfo de los humildes sobre sus opresores. Para Demetrio, Anto, don Bruno Cámac, la felicidad es el librarse de las fuerzas que producen la alienación de los impotentes, el encuentro con el poder que permite rehacer el mundo en la imagen y semejanza de un icono de armonía y paz, el rechazo categórico de la violencia que tiene toda transacción social de la realidad en que viven. Es decir, que quedamos en posición similar a la famosa fórmula que predica que la recanalización del impulso sexual hacia fines de más alta valoración social es la base de una sociedad más o menos racional. Los personajes de Arguedas jamás pasan por la experiencia del amor romántico. Los héroes se extasían en la intensidad de la conquista política o de la visión mística, en lenguaje un tanto parecido al que desde Dante ha signado los códigos del amor humano. Son los personajes que en los textos de Arguedas merecen el apelativo de «anticristo», «condenado», "yegua», «cerdo» los que conocen el placer del sexo, un sexo que emplea al otro siempre en contra de su voluntad. El encuentro de compasión entre dos seres comparables en humanidad (ni ángel ni bestia), el sentimiento de armonía y satisfacción que el acto sexual apasionado es capaz de brindar no tiene lugar en un mundo donde los actos sexuales implican un choque entre dos seres marcados por la disparidad más intensa y obvia.

Es precisamente esta conciencia de la disparidad más profunda, es decir, de la alienación, lo que gobierna el significado de la sexualidad y el acto sexual en los textos de Arguedas. Un simple catálogo de las parejas ilustra sin dejar duda alguna la incompatibilidad social, individual y hasta física y mental de los participantes en esos desencuentros humanos que son los actos sexuales en Arguedas. Al presentar este catálogo sigo el orden cronológico de publicación de los textos, porque este orden imbrica una cierta evolución, más bien una atenuación, en el gra- 
do de disparidad $\mathrm{y}$, por tanto, de alienación que compenetra la experiencia sexual de los personajes. Uso aquí el lenguaje de Arguedas para designar la posición económica, social, mental y hasta espiritual de sus personajes porque así quedan cifrados en metáforas que pulsan dentro de la estructura social que ellos avivan y en la que se saben artificios de valores. Parejas:

1) Justina/sierva-Don Froylán/hacendado/patrón («Warma Kuyay», 1934).

2) La Opa/demente/huérfana-los colegiales/jóvenes sanos (Los ríos profundos, 1958).

3) a) Rosita/«Invertido»-Puñalada, b) Mariví/poderoso criminal«Clavel»/niño raptado (El sexto, 1961).

4) E1 forastero/peruano en Guatemala-María/puta («El forastero», 1964).

5) a) Don Bruno/hacendado-La Kurku/huérfana/sirvienta/enana, b) Don Bruno/hacendado-mestizas pobres o de mala vida (Todas las sangres, 1964).

6) a) El caballero/hacendado-Doña Gabriela/tía pobre, b) E1 caballero/hacendado-Doña Gudelia/mujer de ganadero próspero, c) Mayordomo del caballero-santa crucina de mala vida ( $\mathrm{El}$ horno viejo», 1966).

7) a) Ambrosio/guitarrista-Hercilia/la hija del hacendado, b) Santiago/niño inocente-Marcelina/lavandera borracha ( La huerta», 1966).

8) a) Escritor famoso/escritor en estado de depresión-puta, b) Obreros en Chimbote-putas (El zorro de arriba y el zorro de abajo, 1971).

Se observa inmediatamente una gran distancia de clase entre los hombres y las mujeres, con la excepción clarísima del forastero y de los personajes de Zorros. En general, las mujeres no sólo pertenecen a una clase más baja, sino que es una clase abierta y lúcidamente oprimida por la clase, la más alta posible, que le corresponde al hombre, el que como patrón/caballero simple y llanamente viola a Justina, a doña Gabriela, a doña Gudelia y a la Kurku. Aunque en el caso de doña Gabriela, "amante» del caballero, y en el de doña Gudelia, que fue al horno viejo por hacer un cosquilloso strip-tease con el caballero, parecería que ellas participan libremente; las escenas que Santiago atestigua y narra representan definitivamente violaciones en que las mujeres se resisten, lloran y rezan sin remedio. Santiago, el escandalizado narrador, deja bien en claro la relación dispar de poder físico, social y hasta policial entre los dos términos de la pareja, implicando sin reservas la con- 
dena que la conducta que el abusivo hacendado, su señor, le merece. Al colocar los motivos narrativos, Santiago los coloca con su carga moral de manera que su discurso es de doble flujo. El es juez y víctima, y como víctima se compenetra con las mujeres a quienes presenta en postura análoga a la suya: huérfanas, indefensas, tiernas, devotas, compasivas. Si él es niño, ellas para él son madres dolorosas. Desde su impotencia, todas las víctimas juzgan al poderoso. En el caso de Justina, Santiago y el Kutu fallan por la muerte de don Froylán. Una muerte que en el código del honor en el teatro español le corresponde al Kutu, pretendiente posible a Justina, pero que, como indio, Kutu no puede efectuar. Por tanto, la justicia se pospone hasta que Santiago, a quien históricamente le corresponde el poder pasar de la impotencia al poder, se haga abogado y pueda así reivindicar sus derechos de ideal enamorado.

La visión infernal del sexo que aterra a Santiago no se basa sólo en el forcejeo físico y en inapelable abuso de los débiles y tiernos, sino también en la desigualdad de clase en que las "parejas» están inscritas. La mera sugerencia de que la señorita Hercilia, la joven-pura junto con quien él presencia el acto sexual entre un burro hechor y una yegua, haya tenido un libre encuentro con el charanguero, su amigo Ambrosio, llena a Santiago del mismo asco, cólera y terror que sintió al presenciar las violaciones de las señoras. Su amigo charanguero se transforma en «cerdo» y «bestia» y Santiago no puede soportar estar a su lado. Huye de él, angustiado y torturado por la idea de que las mujeres "gocen» de tan terrible experiencia. Para Santiago, las señoritas constituyen una idealidad tan pura como las nieves de los altos picos en que él busca redención por sus «pecados» o encuentros sexuales. Para Santiago y su necesidad de paz, de orden en el mundo, es absolutamente necesario creer que «la mujer sufre, que ese sufrimiento hace que la mujer sea más que la estrella y como la flor amarilla, suave, del sunchu, que se desmaya si el dedo peludo del hombre sucio la toca» (Todos los cuentos, p. 185). Tal es así que al quedar convencido por Ambrosio, hombre de experiencia, de que a las mujeres les gusta el sexo y no se limitan a sufrir para mitigar los "pecados» de los hombres, y al tener que aceptar como prueba de esa tesis que la señorita Hercilia está encinta de Ambrosio, la escena que sigue nos presenta a un Santiago sin rumbo, deprimido y desmoralizado. Huérfano de toda esperanza, se va a cobijar bajo la tierna sombra de un sauce llorón que se le presenta como «una mujer rendida». Es allí donde, irónicamente entre sueño y vigilia, se le presenta la borracha Marcelina, con sus larguísimos pelos rojos y olor a penetrante orina, Santiago, sin fuerzas ya para luchar contra el mal, accede a la invitación de esa mujer grande, blanca y gorda. Santiago no 
parece tener conciencia de sus actos. Se limita a informarnos que Marcelina le comenta, la única instancia de palabra entre ellos, que es un «muchacho corrompido» que ya "sabe». Santiago se presenta como si hubiera obedecido a una fuerza que está más allá de toda voluntad humana. Como un sonámbulo deja ese huerto habitado por pájaros y árboles amigos y caminando casi inconsciente va a dar al río, en cuyas aguas quiere pero no puede lavarse, desprenderse del fétido olor que invade su ser.

Este momento de entera alienación es la culminación de toda una serie de desengaños en cuanto a su idealización de las jóvenes-puras. E1 primero fue la violación de Justina, a la que Santiago respondiera rehusando hacer uso de ella cuando Kutu se la ofrece ya «caída». Pero después del horno viejo y oír la violación de doña Gabriela, al saber lo de Hercilia, Santiago ya no resiste más. Toda su esperanza se ha consumado. El saber que las jóvenes-puras son también seres sexuales es como si los ángeles hubieran sido derribados por Satanás. Ya sin fuerzas para insistir en su visión, en su negación de la sexualidad de los Buenos, entrega su carne a Marcelina, la peluda y hedionda imagen del diablo. Por años Santiago se mete con Marcelina. Por años se arrastra hasta las más altas nieves del Arayá (Todos los cuentos, p. 188). «Ya no se lavó. Le rendía el hedor que todo su cuerpo exhalaba... ¡Cuántos años estuvo yendo de la huerta al Arayá? No se acordaba. En el camino maldecía, lloraba, prometía y juraba no revolcarse más sobre el cuerpo grasiento de la Marcelina. Pero la huerta se hacía, en ciertos instantes, más grande que todos los cielos; esa huerta con su sauce llorón, con ese hedor, con los orines de la borracha. Y cada vez le atacaba el anhelo de ir donde el padre Arayá, cuando los pelos de la Marcelina se erizaban y de allí brotaba algo como el asco del mundo.»

La infantil visión de que la mujer (madre, hermana) es un ángel entra en ciega dialéctica con la reportada y experimentada realidad de que la mujer es también un ser sexual. Esta contradicción, esta lucha de oposiciones no encuentra salida en Arguedas hasta el momento en que «el forastero», hombre que pasa por una sociedad a la que no pertenece, se ve poseído de suficiente soltura (desarraigo de estructuras míticas y sociales) como para pasar la noche con una puta miserable y reconciliar así su orfandad con la de ella, poder así exclamar, a pesar de sus repugnantes babas: «iNo conocía a la mujer! ¡No, no la conocía...! iSólo ella, ella sola...!» (Todos los cuentos, p. 163).

La dialéctica que escinde a la mujer entre ángel o yegua, esa misma dialéctica le presenta al hombre la alternativa de escoger entre señoritas puras y putas o dementes, tiene como consecuencia lógica el negar la 
corporeidad de los seres sexuales humanos y relegarla al mundo de las bestias. Los encuentros que vemos expresan más la violencia individual y social entre hombres y mujeres que la corporeidad del acto sexual mismo. Tan consciente está Arguedas de la humillación, del rebajamiento humano, que el ejercicio de la sexualidad implica que narrativamente interpone dos escenas de violación sexual y social (patrón-doña Gabriela, patrón-doña Gudelia) con el encuentro sexual entre un burro hechor y una yegua, el que sí está descrito en detalle de movimiento y sensación corpórea. Este colindaje reverbera por todo el texto de «E1 horno viejo» y hasta invade "La huerta", cuento que forma parte de la misma narrativa del «Horno viejo». En ambos la negación del cuerpo como situs del placer lícito, del goce del bien, imbrica en sí la gama de valores mariológicos que caracteriza la visión del sexo en Arguedas.

El encuentro entre el burro hechor y la yegua es algo que Santiago ya ha visto en otras ocasiones. Sin embargo, él narra el episodio temblando de terror porque quisiera evitar que la señorita a quien él acompaña y aspira no lo viera. La tensión narrativa se desplaza del encuentro entre los dos animales a lo que la señorita verá o no verá: «El Jerónimo soltó al hechor en el corral cuando la joven hija del hacendado estaba en el corredor. La acompañaba Santiago. La joven cantaba mejor que la calandria» (Todos los cuentos, p. 173). Ver y no ver, es decir, constatar con la irremediabilidad ocular las sospechas, fantasías y retazos de rumores de una realidad que por visual se hace innegable, es el verdadero juego narrativo de esta escena: «El garañón se lanzó a la carrera, rebuznando con un júbilo que dejó rígido el rostro de la joven. Porque el burro enorme iba con su miembro viril aún más enorme a embestir a una yegua que estaba al otro lado del muro del corral, a pocos metros de la señorita... El garañón le hundió el miembro; mordió el lomo a la yegua» (Todos los cuentos, p. 173).

Es más, el terror de ver se duplica en la angtustia de ser visto, en el momento en que la conciencia del mundo y, por tanto, de uno mismo se transforma. Ser visto en este instante constituye una violación mayor que la que se podría hacer con cualquier parte del cuerpo. A diferencia del señor, que quiere ser visto para escandalizar, la señorita no quiere ni ver ni menos ser vista viendo. Así, pues, Santiago no sólo quiere prevenir que la señorita vea el negativo de lo que él haría o tendría que hacer con ella si sus aspiraciones adquirieran algún día forma lícita, social y carnal, sino que se atormenta por evitar que la señorita vea que él le está mirando su cara-conciencia y que al hacerlo está penetrando en las capas más profundas de su intimidad sexual. En ese momento de arrebato el mundo entero se transforma en una 
suerte de escena expresionista: «Los dos animales se movían, y el río fangoso se convirtió en sangre pura y terrible que empezó a subir desde los pies hasta la frente de la jovencita. Santiago miraba... Sí, ella cantaba mejor que las calandrias, pero en ese instante, viendo el asalto y los movimientos del garañón, su rostro enrojeció desde dentro, como lirio blanco que se transforma en un trozo de crepúsculo que es luz roja de uno mismo más que del sol y del cielo» (Todos los cuentos, p. 174). El doble voyerismo de Santiago recibe su temido castigo. Inmediatamente, y sin compasión alguna, el ángel animalizado, es decir, sexualizado, lo echa de su lado-cielo, no dejando de recordarle su presente orfandad social, su desclase o limbo: "Tú me miras, bestia. ¿Por qué me miras, botado, muerto de hambre?" (Todos los cuentos, p. 174).

La experiencia del libre placer del cuerpo se da únicamente en esta escena y en toda la obra de Arguedas, escena entre dos poderosos animales que al retratar en su sexualidad a los dos humanos que los miran escandalizan la conciencia de un orden que como privilegio de clase niega a unos (señoritas) la sexualidad e impone en otros (cholas) el ser instrumento involuntario de ella. No son sólo las «buenas mujeres» las que deben someterse a la «maldición» del sexo. «Malditos»son también los chicos del colegio en Los ríos profundos, Santiago en los cuentos de Amor mundo y don Bruno en Todas las sangres. Sin embargo, Santiago y don Bruno, a diferencia de la mayoría de los chicos en el colegio (Peluca, que no se arrepiente al final, se vuelve loco), viven atormentados por sus prácticas sexuales y se arrepienten en cada recodo del camino. Expían sus culpas para no condenarse (loquearse, como el Peluca), es decir, para no verse para siempre separados del ser que añoran ser, para no sufrir de autoalienación en el más último grado. Imposible sería salvar al mundo siendo el héroe salvador un «condenado». Don Bruno expía, imponiéndose el plan de salvaguardar a sus indios y a sí mismo del deseo de dinero, Santiago hace peregrinaciones al Arayá. Mortifica la misma carne que se une a Marcelina, a su hedor perenne. Ambos héroes caídos tienen encuentros sexuales movidos por una fuerza mayor que los lleva a actos detestables con mujeres física y mentalmente deformes y repulsivas. Los tres «oprimidos» e «inocentes jóvenes», Palacitos, Santiago, Bruno, son víctimas del deseo sexual de seres gordos, hediondos, babosos, blancos; y en el caso de la Kurku contrahecha, antihumana hasta el punto de la desproporción física del enano. No debe pasarse por alto que los enanos tradicionalmente inspiran horror porque están asociados con lo desconocido y los poderes maléficos del más allá. Y así es como la Kurku figura en Todas las sangres. Para Anto, ella es una «criatura de Dios», frase ambivalente, ya que Dios, «el Dios de la igle- 
sia», es tanto creador del mal como del bien. Criatura de Dios parece más significar lo que en otra cosmología se apelaría monstruo de la naturaleza, algo incomprensible, un reto a los límites de la razón de la cultura. Una innegable presencia sensorial que, sin embargo, carece de sentido metafísico a no ser que se la tome como la expresión irracional de la cólera de Dios, es el lugar que ocupa la Kurku en la estructura ética y metafísica del texto de Arguedas.

A diferencia de la Kurku, la bestialidad, es decir, la deshumanización que caracteriza a la Opa y a la Marcelina (la Opa también se llama Marcelina), va marcada por dos aspectos contradictorios. Mientras que la animalidad que gobierna su cuerpo es responsable por su agresiva conducta sexual, esa misma bestialidad las excusa de ser «pecadoras», ya que su idiotez las previene del poder de ejercer juicios morales y las hace un tanto sufridoras. La Kurku, sin embargo, y a pesar de su mayor deformidad humana, no es demente y expresa inequívocamente que le interesa la vida sexual, lo cual allana un poco el «pecado» del joven Bruno. La asociación de la Kurku con poderes maléficos se hace aún más clara porque a la razón de Anto hasta los animales dejaron de cumplir con su deber la fatídica noche y no hicieron ningún ruido en el corral. El mismo poder que le asiste a la Kurku es el que persigue al dorado y caído angel Bruno, quien al violar a la enana trae la maldición eterna sobre su casa y el pueblo entero. Desde el día de esa caída, crimen inaudito y, por tanto, imperdonable a medios humanos, el Señor Padre Aragón de Peralta se dio al alcohol, desheredó a sus hijos, descuidó su hacienda y convirtió a su mujer en reclusa al cuidado de la misteriosa enana.

En el crimen del joven Bruno con la Kurku atendemos analógicamente al mito de Adán y Eva y a su transformación de seres angélicos, es decir, asexuales, en seres sexuales y, por tanto, criminales. La Kurku, en su deformidad física, su astucia y arrogancia, combina en sí a Eva y la serpiente. Don Bruno, al caer tan profunda e inhumanamente en lo prohibido -es como si Adán hubiera conocido no sólo a Eva, sino a la serpiente también-, no sólo ocasiona la cólera y la venganza del Padre, sino que lo enloquece, causando así que éste expulse del Paraíso a los hijos y después, insatisfecho aún, destruya su propia creación: el pueblo, su hacienda, su fortuna, sus vecinos, terminando por su propia expulsión (suicidio).

Material y narrativamente, la caída de don Bruno está escenificada en la primera "caída de Santiago", cuando entre juramentos y procaces insultos, el condenado Señor despierta al inocente, que duerme todavía en el regazo de su madre. Toda la historia transcurre en la oscuridad. 
El niño no sabe adónde va, pero está a la expectativa de algo aterrador. El «condenado» que lo guía escoge el camino más escabroso y constantemente le pregunta si los espinos que bordean el camino y los muros que le hace saltar le hacen doler. Su destino final es el cuarto oscuro de la prima del condenado. Allí, Santiago, ya ciego de dolor, no podrá ver nada. Escuchará las protestas de la mujer, en cuya voz reconoce a la madre de sus amigos. Esa noche Santiago no sólo desciende para conocer el sexo, sino también el incesto. Enloquecido por el dolor, Santiago, como don Bruno, huye del paraíso maternal en un caso, paternal en el otro. No sentirá, sin embargo, el sentimiento de suciedad y persecución que embriaga a don Bruno hasta que después de tanto ver $\mathfrak{u}$ oír experimenta en carne propia su sexualidad. Aquí el descenso es ya completo, y aunque parapeta todos sus sentidos, nada mitiga el sentimiento de quebrantamiento y alienación que anegan los días del joven. Sólo la reconciliación con los simples dioses hacen mella al dolor que el condenado señor quería que sintiese. Don Bruno, católico devoto, frente a un Dios mucho más ambiguo y reticente no encuentra consuelo.

La estructura causativa del mito de Adán y Eva no tiene otra salida que culpar a la mujer por la existencia de la sexualidad, por la necesidad de ser dos, de necesitar del otro. Dios mismo se encarga de examinar a Adán castigándolo y premiándolo al mismo tiempo con el deber del trabajo. A fin de cuentas, con su propio esfuerzo puede expiar la ofensa y salvarse. Con Calvino hasta llega a hacerse rico y poderoso. Para la mujer, sin embargo, el equívoco de los comestibles no trae más que miseria, sumisión y sufrimiento. La mujer razona el mito, no tiene juicio, se equivoca $y$, peor aún, causa que el hombre cometa errores, entre ellos el error de aceptar y querer satisfacer su sexualidad. Ella, pues, como se repite hasta el cansancio en la obra de Arguedas, debe sufrir para así expiar su criminal sustancialidad, para compensar por su mera presencia desequilibradora. Ahora bien, si esa mujer verdaderamente quiere participar en el orden más o menos restaurado por la autoridad masculina, lo que le queda es consolar al hombre que «peca» con su sexualidad-maldición. E1 modelo es aquí la joven mestiza, que jamás cuestiona a don Bruno y que en adoración le va a dar un hijo hombre. Para mayor consuelo aún, existen las señoritas, las vírgenes que ignoran su propia sexualidad, las que jamás escuchan a la serpiente y que se rehúsan a saber cómo es que cumplen con sus deberes reproductivos. Las contradicciones de la divinidad también se ignoran y no se anda mirando lo que hacen los animales. Las señoritas constituyen el mito reconstructivo que responde al desastre del huerto bíblico y del huerto andino, espacios divinos que inexplicablemente admiten la presencia de 
serpientes y borrachas. Espacios sagrados que inesperadamente quedan invertidos en su sustancia y sentido y por cuya inversión el hombre es angustiosa e inexplicablemente responsable, es decir, criminal.

La tesis mariológica que trashuma la dinámica afectiva, física y metafísica, del sexo en Arguedas no puede ser ni más clara ni menos poderosa. No hay que olvidar al mismo tiempo que esta tesis, a nivel mítico, expresa también las diferencias abismales de poder que existen en una sociedad en que todo hombre está sujeto, encajonado, en el poder de otro, y todos y cada uno de esos individuos viven sometidos bajo su autoridad a una mujer o a una clase de mujeres. Esta desastrosa sexualidad al nivel mitológico, político y social empieza a resquebrajarse en los textos más tardíos de Arguedas (Los zorros), cuando los hombres, libres de las amarras de las estructuras de sus pueblos, en lucha con un medio sin perfil, comienzan a vislumbrar en la mujer a su prójimo. 
